\title{
Phytochemical and Antimicrobial Properties of the Aqueous Ethanolic Extract of Saccharum officinarum (Sugarcane) Bark
}

\author{
Eneh Frank Uchenna ${ }^{1}$, Okechukwu Amara Adaeze ${ }^{1} \&$ Adindu Chukwuemeka Steve ${ }^{1}$ \\ ${ }^{1}$ Department of Applied Biochemistry, Nnamdi Azikiwe University, Awka, Anambra State, Nigeria \\ Correspondence: Eneh Frank Uchenna, Department of Applied Biochemistry, Nnamdi Azikiwe University, \\ Awka, Anambra State, Nigeria. E-mail: uchefeneh@yahoo.com
}

Received: June 1, 2015 Accepted: July 21, 2015 Online Published: September 15, 2015

doi:10.5539/jas.v7n10p291 URL: http://dx.doi.org/10.5539/jas.v7n10p291

\begin{abstract}
Phytochemical analysis and antimicrobial activities of the aqueous ethanolic extract of Saccharum officinarum were carried out. The antimicrobial activity was screened by disc diffusion method while the analysis of the different phytochemicals was carried out using standard methods. The result showed that the extract had inhibitory effects on the gram negative bacteria (Escherichia coli and Pseudomonas aeruginosa). The effect of the extract was minimal on Staphylococcus aureus, a gram positive bacteria suggesting some degree of resistance by the organism. The result of the phytochemical screening showed that extract contains saponins, tannins, flavonoids and reducing sugars. The findings show that the plant bark extract has bactericidal activity and could be used in the control and treatment of bacterial infection especially the gram negative bacteria.
\end{abstract}

Keywords: antimicrobials, microbial culture, phytochemicals, sugarcane, zones of inhibition

\section{Introduction}

Microorganisms have been implicated in some disease conditions. The frequency of life-threatening infections caused by pathogenic microorganisms has increased worldwide and is becoming an important cause of morbidity and mortality in immunocompromised patients in developing countries (Al-Bari et al., 2006). More worrying is the increasing economic implication of arresting these microbial infections. The increasing prevalence of multi-drug resistant strains of bacteria and the recent appearance of strains with reduced susceptibility to antibiotics raised the specter of untreatable bacterial infects and adds urgency to the search for new infectionfighting strategies (Zy et al., 2005; Rojas et al., 2006). The search for newer antimicrobial sources is therefore necessary and should be a continuous process.

Plants are the cheapest and safer alternative sources of antimicrobials (Doughari et al., 2007). For a long time, natural products from plants have been used by man in the area of health. The antimicrobial properties of plants have been studied by a number of researches worldwide and many of them have been used as therapeutic alternatives because of their antimicrobial properties (Adriana et al., 2007). Plants generally produce many secondary metabolites which constitute an important source of microbicides, pesticides and many other pharmaceutical drugs (Mahalingam et al., 2011). Sugarcane (Saccharum officinarum) is a full growing monocotyledonous crop that is cultivated in the tropical and subtropical regions of the world primarily for its ability to store high concentrations of sucrose or sugar in the stem. Modern sugarcane varieties that are cultivated for sugar production are founded on inter-specific hybrids between S. spontaneum and S. officinarum. Sugarcane belongs to the grass family (Poaceae). The main product of sugarcane is sucrose, which accumulates in the stalk internodes. Sucrose extracted and purified is used as raw material in human food industries or is fermented to produce ethanol. Apart from sucrose, sugarcane products have been used for several other purposes. Abas et al. (2003) has reported the antioxidant properties, repair and tolerance of DNA damage in different cultivars of sugarcane leaves. The sugarcane juice contains flavonoids such as apigenin, luteolin and fricin derivatives and among phenolics, hydroxycinnamaric, caffeic and sinapic acid, representing a total content of around $160 \mathrm{mg} / \mathrm{L}$ (Joaqium et al., 2006) whereas, sugarcane leaves contains luteolin-8-C-(rhamno-sylglucoside) as major compound with radical scavaging activity (Fabiana et al., 2008). Policosanol, a component of sugarcane wax was believed to reduce plasma total cholesterol and low density lipoprotein cholesterol levels when administered orally (Castano et al., 2002; Gamez et al., 2003). This finding is contrary to Francini-Pesenti et al. (2007) which showed that policosanol has no lipid lowering effects (at doses of $20 \mathrm{mg}$ daily) in subjects with primary 
hypercholesterolemia. Sugarcane is a principal raw material for the sugar industry as $70 \%$ of the world's sugar comes from it. Besides sugar production, large number of population in the topics and subtropics relishes its juice and consume raw cane (Abbas et al., 2013).

Despite all the works that have been done on the leaves and juice of sugarcane, literature is scarce on the importance of the bark. This research is motivated by the fact that sugarcane which is rich in sucrose should be susceptible to attack by microorganisms. This is not the case suggesting there may be a bioactive agent in the bark that prevents this. This work is aimed at exploiting the potentials inherent in the bark of this plant for antimicrobial purposes.

\section{Materials and Methods}

\subsection{Plant Collection}

The sugarcane stem was collected from a cultivated farmland at Trans-Ekulu stream Bank, Enugu, Enugu state, Nigeria. The plant was identified at the Botany Department of Nnamdi Azikiwe University, Awka, Anambra State, Nigeria.

The bark was thoroughly washed, peeled and cut into pieces to expose a larger surface area for drying. The cut pieces were dried in on oven at $55{ }^{\circ} \mathrm{C}$ and an electrical blender was used to grind this into a power. This was stored in airtight containers for further use.

\subsection{Plant Extraction}

Powdered sample $(800 \mathrm{~g})$ was extracted in one liter of $70 \%$ ethanol in a conical flask. The conical flask was thoroughly shaken, plugged with a rubber cork and allowed to stand at room temperature for 24 hours with occasional manual agitation of the flask using a sterile rod. At the end of 24 hours, the extract was filtered using sterile whatmann no. I filter paper. The resulting filtrate was concentrated in a glass beaker using a water bath. The percentage yield of the extract was calculated using the formula:

$$
\text { Percentage yield of extract }=(\text { Weight of extract/Weight of sample of sugarcane }) \times 100
$$

\subsection{Microorganisms}

Pure culture of microorganisms used for the evaluation of antimicrobial potential of the sugarcane bark extract were; Escherichia coli, Pseudomonas aeruginosa (Gram negative bacteria) and staphylococcus aureus (Gram positive bacterium). The organisms were all locally isolated pure cultures obtained from Peace Diagnostic Centre, Awka.

\subsection{Phytochemical Analysis}

Phytochemical analysis for qualitative detection of alkaloids, tannins, saponin, flavonoids, cardiac glycoside, reducing sugars, carbohydrates and anthracine glycosides was carried out on the powered extract as follows:

\subsection{Determination of Alkaloids}

The extract $(0.5 \mathrm{~g})$ was diluted with $10 \mathrm{ml}$ of acid alcohol, boiled and filtered. $2 \mathrm{ml}$ of diluted ammonia was added and shaken gently to extract the alkaloidal base. The chloroform layer was extracted with $10 \mathrm{ml}$ of acetic acid. This was divided into two portions. Meryer's reagent was added to one portion and Wagner's reagent to the other. The formation of a cream (with Meryer's reagent) or reddish brown precipitate (with Wagner's reagent) was taken as positive for the presence of alkaloids (Trease \& Evans, 1989; Oluduro, 2012).

\subsection{Test for Saponins}

The ability of saponins to produce frothing in aqueous solution was used as screening test for saponins. Powdered extract $(0.5 \mathrm{~g})$ was shaken with distilled water in a test tube. Frothing which persisted on warming was taken as evidence for the presence of saponins (Sofowora, 1982).

\subsection{Determination of Tannins}

The extract $(5 \mathrm{~g})$ was stirrred with $100 \mathrm{ml}$ of distilled water, filtered and ferric chloride reagent added to the filtrate. A blue-black green precipitate indicated the presence of tannins (Trease \& Evans, 1978).

\subsection{Determination of Flavonoids}

Powdered sample $(2.0 \mathrm{~g})$ was detanned with acetone. The sample was placed on a hot water bath for all traces of acetone to evaporate. Boiling distilled water was added to the detanned sample. The mixture was filtered while hot. The filtrate was allowed to cool and $5 \mathrm{ml}$ of $20 \%$ sodium hydroxide was added to equal volume of the filtrate. A yellow solution indicates the presence of flavonoids (Trease \& Evans, 1998; Sofowora, 1983). 


\subsection{Test for Cardiac Glycosides (Keller-Killani Test)}

The extract $(1.0 \mathrm{~g})$ was treated with $2 \mathrm{ml}$ of glacial acetic acid containing one drop of ferric chloride solution. This was underlayed with $1 \mathrm{ml}$ of concentrated sulphuric acid. A brown ring at the interface indicates a deoxysugar characteristic of glycosides. A violet ring may appear below the brown ring, while in the acetic acid layer, a greenish ring may form just gradually throughout the thin layer.

\subsection{Detection of Carbohydrates}

$1.0 \mathrm{~g}$ of extract was dissolved in $5 \mathrm{ml}$ of distilled water and filtered. The filtrate was divided into 2 portions and was used to test for the presence of carbohydrates using the following reagents.

\subsubsection{Molisch's Test}

The filtrate was treated with 2 drops of alcoholic $\alpha$-naphthol solution in a test tube. The formation of the violet ring at the junction indicates the presence of carbohydrates.

\subsubsection{Fehling's Test}

Filtrate was hydrolysed with dil. $\mathrm{HCl}$, and then neutralized with alkali and warmed with Fehling's A \& B solutions. The formation of brick red precipitate indicates the presence of reducing sugars.

\subsubsection{Test for Anthracene Glycosides (Borntrager's Test)}

About $10 \mathrm{mg}$ of the extract was placed in a dried test tube and $10 \mathrm{ml}$ of chloroform added. The mixture was shaken for $5 \mathrm{~min}$ and filtered with Whatman No. 1 filter paper. To $3 \mathrm{ml}$ of the filtrate equal volume of ammonia solution was added and shaken. Formation of a bright pink-red colour in the upper aqueous layer indicates the presence of free anthracene glycosides (Evans, 2002).

\subsection{Antimicrobial Assay}

\subsubsection{Preparation of Antibiotic Discs}

The concentrated ethanolic extract of sugarcane bark weighing $0.5,1.0$ and $1.5 \mathrm{~g}$ were dissolved separately in $5.0 \mathrm{ml}$ of distilled water to give 10,20 and $30 \%$ concentrations respectively. Filter papers of known diameter were carved out and soaked in the different concentrations of the extract.

\subsubsection{Preparation of Nutrient Agar Medium}

A conical flask was sterilized by boiling in water bath for about 45 minutes and $7.0 \mathrm{~g}$ of nutrient agar was dissolved in $250 \mathrm{ml}$ of distilled water inside the already sterilized conical flask. The conical flask was corked and the agar was allowed to soak for 10 minutes after which sterilization followed by heating over a Bunsen burner until boiling was attained. It was then cooled to about $37{ }^{\circ} \mathrm{C}$ and $25 \mathrm{ml}$ of the agar was poured into each sterile disposable petri dish and allowed for 12 hours to gel.

\subsubsection{Inoculating/Culturing of Microorganisms}

A primary innoculum was made first on the media, then the organism (innoculum) was spread on the whole petridish by streaking. This procedure was used for transferring the organisms (Echerichia coli, Psendomonas aeruginosa and Staphylococcus aureus) separately into their culture media. The antibiotic (antimicrobial discs) were placed on the inoculated organisms (at the centre of the media) using sterile forceps. The petridishes were labeled according to the different microorganisms and the concentrations of their antibiotic discs. The organisms were incubated at $37^{\circ} \mathrm{C}$ for 24 hours. Their zones of inhibition in $\mathrm{cm}$ was determined and hence their percentage zones of inhibition calculated. A disc of diameter $2.40 \mathrm{~cm}$ was used. 


\section{Results}

Table 1. Phytochemical analysis of the aqueous ethanolic extract of the bark of Saccharum officinarum

\begin{tabular}{ll}
\hline Phytochemical & Observation \\
\hline Saponin & + \\
Tannins & + \\
Flavonoids & + \\
Alkaloids & - \\
Cardiac glycosides & + \\
Reducing sugars & + \\
Carbohydrates & + \\
Anthracene glycosides & + \\
\hline
\end{tabular}

Note. + = Indicated; - = Not indicated.

Table 2. Antimicrobial Activity of the Ethanolic extract of the Bark of Sacchaarum officinarum on the different organisms

\begin{tabular}{llll}
\hline Organism & \% Conc. of extract & Zone of inhibition & \% zone of inhibition \\
\hline Escherichia coli & 10 & 1.10 & 45.83 \\
& 20 & 0.90 & 37.50 \\
& 30 & 0.60 & 25.00 \\
\hline Pseudomonas aeruginosa & 10 & 1.10 & 45.83 \\
& 20 & 1.20 & 50.00 \\
\hline Staphylococcus aureus & 30 & 1.30 & 54.16 \\
& 10 & 0.10 & 4.17 \\
& 20 & 0.00 & 0.00 \\
\hline
\end{tabular}

The result shows that the extract had inhabitory effects on the gram negative bacteria (Escherichia coli and Pseudomonas aeruginosa) and mild effect on Staphycococcus aureus (Gram positive bacterium). The inhibitory effect was highest for Pseudomonas aeruginosa and had a dose dependent action. The higher doses gave a greater zone of inhibition. This was in the reverse for Escherichia coli where higher doses gave a reduced zone of inhibition. Increased doses of the extract showed no inhibitory activity on Staphylococcus aureus.

\section{Discussion}

Microbial infections are common among the human population. A lot of efforts have been made in containing these infections. The first line of action is usually the use of synthetic antibiotics. Recently, there has been a growing trend of antibiotic resistance thereby rendering some of these antibiotics ineffective. In addition to this, some of these synthetic antibiotics have dangerous side effects. For example, parabens are widely used as preservatives by cosmetic and pharmaceutical industries basically because of their bactericidal and fungicidal properties. However, their use is becoming increasingly controversial because they have been found in breast cancer tumors (an average of 20 nanograms/g of tissue) (Harvey \& Everett, 2004; Darbre et al., 2004). They have also displayed the ability to slightly mimic estrogens (a hormone known to play a role in the development ob breast cancer) (Harvey \& Everett, 2004). Although there has not been a report of a direct link between parabens and cancer (Golden et al., 2005), a lot of caution is still needed in their use. All these drawbacks in the use of synthetic antibiotics call for an alternative approach and plant based therapies provide this platform.

The bark of sugarcane demonstrated a strong antibacterial activity on the gram negative bacteria indicating its high antibacterial potential and effectiveness in the treatment of wound infections. P. aeruginosa showed the 
highest zone of inhibition at the highest concentrations of the extract tested $(30 \%)$. This suggests that higher concentrations of the extract may be needed to inhibit the growth of $P$. aeruginosa but once the threshold is attained, it becomes very sensitive. The antibacterial effect of the extract was minimal for $S$. aureus suggesting some degree of resistance by the organism.

The result of the phytochemical screening revealed the presence of saponins, tannins, flavonoids, reducing sugars and carbohydrates. Saponins, tannins and carbohydrates were strongly indicated while alkaloids and cardiac glycosides were absent. These phytochemicals have been suggested to be responsible for the antimicrobial effect of some plant extracts (Rahman et al., 2009; Mahesh \& Satish, 2008; Ankri \& Mirelman, 1999; Cushnie \& Lamb, 2005). Flavonoids have been reported to possess many useful properties including enzyme inhibition, anti-inflammatory activity, oestrogenic activity, antimicrobial activity (Havsteen, 1983; Harbone \& Baxter, 1999), antiallergic activity and antioxidant activity (Abbas et al., 2013). The antibacterial activity of flavonoids is being increasingly documented. Extracts from plants with a history of use in folk medicine have been screened in vitro for antibacterial activity by many research groups (Cushnie \& Lamb, 2005) Some of the proposed mechanisms for the antibacterial activity of flavonoids include; inhibition of nucleic acid synthesis (Mori et al., 1987), inhibition of cytoplasmic membrane function (Tsichuya \& Linama, 2000) and inhibition of energy metabolism (Haraguchi et al., 1998).

Saponins have also been reported to have antibiotic activities. Soetan et al. (2006) evaluated the antimicrobial activity of saponin extract of Sorghum bicolor L. They were able to show that the $\mathrm{n}$ - butanol purified saponin extract of S. bicolor had inhibitory effect on gram negative organisms.

\section{Conclusion}

The activity of the aqueous ethanolic extract of $S$. officinarum bark is indicative of the presence of bioactive compound(s) with antibiotic potentials. Sugarcane bark is edible and so will potentially produce antimicrobial compounds that are safe and more tolerable by living systems. In view of the increasing resistance to antibiotics by most pathogenic organisms, the discovery of novel active compounds against new targets and the elucidation of their mode of action is a matter of urgency. S. officinarum offers such potential. Furthermore, large volumes of sugarcane bark are produced yearly thereby constituting a huge raw material base for the production of the antimicrobial compound. Further work is needed to purify the extract as this could reveal the actual molecule responsible for the antimicrobial activity.

\section{References}

Abbas, S. R., Ahmad, S. D., Sabir, S. M., Shah, A. H., Awan, S., Gohar, M., ... Rao, A. Z. (2013). Antioxidant activity, repair and tolerance of oxidative DNA damage in different cultivars of Sugarcane (S. officinarum) Leaves. Australian Journal of Crop Science, 7(1), 40-45.

Adriana, B., Almodovarl, A. N. M., Pereirral, C. T., \& Mariangela, T. A. (2007). Antimicrobial efficacy of Curcuma zedoaria extract as assessed by linear regression compared with commercial mouth rinses. Brazilian Journal of Microbiology, 38, 440-445. http://dx.doi.org/10.1590/S1517-83822007000300011

Al-Bari, M. A., Sayeed, M. A., Rahman, M. S., \& Mossadik, M. A. (2006). Characterization and antimicrobial activities of a phenolic and derivative produced byStreptomyces bangladeshiences, a novel species collected in Bangladesh. Res. J. Medicine and Medical Sciences, 1, 77-81.

Ankri, S., \& Mirelman, D. (1999). Antimicrobial properties of allicin from garlic. Microbes and Infections, 2, 125-129. http://dx.doi.org/10.1016/S1286-4579(99)80003-3

Castano, G., Menerodez, R., Mas, R., Amor, A., Fernandez, J. L., Gonzalez, R. L., ... Alvarez, E. (2002). Effects of policosanol and lovastatin on lipid profile and lipid peroxidation in patients with dyslipidemia associated with type 2 diabetes mellitus. Int. J. Clin. Pharmacol. Res., 22, 89-99.

Cushnie, T. P. T., \& Lamb, A. J. (2005). Detection of galangin-induced cytoplasmic membrane damage in Staphylococcus aureus by measuring potassium loss. J. Ethnopharmacol., 101, 243-248. http://dx.doi.org/10.1016/j.jep.2005.04.014

Darbre, P. D., Aljarrah, A., Miller, W. R., Coldham, N. G., Sauer, M. J., \& Pope, G. S. (2004). Concentrations of parabens in human breast tumors. Journal of Applied Toxicology, 24(1), 5-13. http://dx.doi.org/10.1002/jat.958

Doughari, J. H. (2006). Antimicrobial Activity of Tamarindus indica Linn. Tropical Journal of Pharmaceutical Research, 5(2), 597-603.

Fabiana, C. V., Renata, C., Tetiana, O. D., \& Janete, H. Y. (2008). HPLC microfraction of flavones and 
antioxidant (radical scavenging) activity of Saccharum officinarum L. Journal of the Brazilian Chemical Society, 19(5), 903-908. http://dx.doi.org/10.1590/S0103-50532008000500014

Francini-Pesenti, F., Beltramolli, D., Dall'Acqua, S., \& Brocadello, F. (2008). Effect of sugarcane policosanol on lipid profile in primary hypercholesterolemia. Phytotherapy Research, 22(3), 318-322. http://dx.doi.org/10.1002/ptr.2315

Gamez, R., Mendoza, S., Mas, R., Noa, M., Arruzazabala, L., Carbajal, D., ... Mendoza, N. (2003). Comparison of the cholesterol lowering effects and toxicity of D - 003 and lovastatin in normocholesterolaemic rabbits. Drugs R. D., 4, 219-229. http://dx.doi.org/10.2165/00126839-200304040-00002

Golden, R., Gandy, J., \& Vollmer, G. (2005). A review of the endocrine activity of parabens and implications for potential risks to human health. Critical Reviews in Toxicology, 35(5), 435-458. http://dx.doi.org/10.1080/10408440490920104

Haraguchi, H., Tanimoto, K., Tamura, Y., \& Mizutani, K. (1998). Mode of antibacterial action of retrochalcones from Glycyrrhiza inflata. Phytochemistry, 48, 125-129. http://dx.doi.org/10.1016/S0031-9422(97)01105-9

Harborne, J. B., \& Baxter, H. (1999). The Handbook of natural flavonoids (Vol. 1 and Vol. 2). Chichester, UK. John Wiley \& Sons.

Harvey, P. W., \& Everett, D. J. (2004). Significance of the detection of esters of p-hydroxybenzoic acid (parabens) in human breast tumors. Journal of Applied Toxicology, 24(1), 1-4. http://dx.doi.org/10.1002/jat.957

Hausteen, B. (1983). Flavonoids, a class of natural products of high pharmacological potency. Biochemical Pharmacology, 32, 1141-1148. http://dx.doi.org/10.1016/0006-2952(83)90262-9

Joaquim, M. D. A., Mauricio, D. V. N., Adyary, F. L., Franco, M. L., \& Maria, I. G. (2006). Antioxidant activity of phenolic compounds from sugarcane (Saccharum officinarum L.) juice. Journal of plant food for Human Nutrition, 61, 187-192.

Mahalingam, R., Ambikapathy, V., Panneer Selvam, A., \& Prince, L. (2011). Biological activities of some medicinal plants against Setophaeria rostrata causing seeding blight disease in sugarcane. Asian Journal of Plant Science and Research, 1(2), 92-95.

Mahesh, B., \& Satish, S. (2008). Antimicrobial activity of some important medicinal plants and human pathogens. World Journal of Agricultural Science, 4, 839-843.

Mori, A., Nishino, C., Enoki, N., \& Tawata, S. (1987). Antibacterial activity and mode of action of plant flavonoids against Proteus vulgaris and Staphylococcus aureus. Phytochemistry, 26, 2231-2234. $\mathrm{http}: / / \mathrm{dx}$. doi.org/10.1016/S0031-9422(00)84689-0

Oluduro, O. A., Idowu, T. O., Aderiye, B. I., Famuriwa, O., \& Omoboye, O. O. (2012). Evaluation of antibacterial potential of crude extract of Moringa oleifera seed on orthopaedic wounds isolates and characterization of phenylmethanamine and benzyl isothiocyanate derivatives. Research Journal of Medicinal Plant, 6(5), 383-394. http://dx.doi.org/10.3923/rjmp.2012.383.394

Rahman, F., Chowdhury, S., Rahman, M. M., Ahmed, D., \& Hossain, A. (2009). Antimicrobial Resistance Pattern of Gram-negative Bacteria causing urinary tract infection. Stamford Journal of Pharmaceutical Sciences, 2(1), 44-50.

Rojas, J. J., Ochoa, V. J., Ocampo, S. A., \& Munoz, J. F. (2006). Screening for antimicrobial activity of ten medicinal plants used in Colombian folkloric medicine - A possible alternative in the treatment of non nosocomial infections. BMC Complement Altern. Med., 6, 2. http://dx.doi.org/10.1186/1472-6882-6-2

Soetan, K. O., Oyekunle, M. A., Aiyelaagbe, O. O., \& Fafunso, M. A. (2006). Evaluation of the antimicrobial activity of saponins extract of Sorghum bicolor L. Moench. African Journal of Biotechnology, 5(23), 2405-2407

Sofowara, E. A. (1982). Medical plants and Traditional Medicine in Africa Chichester (pp. 109-111). John Willey and Sons, London.

Sofowara, E. A. (1983). Medicinal plants and Traditional Medicine in Africa (2nd ed., pp. 186-256). John Willey and Sons, London.

Trease, G. E., \& Evans, M. D. (1989). A textbook of pharmacognosy (13th ed., pp. 176-180). Builler Tindal and Caussel, London. 
Trease, G. F., \& Evans, W. C. (1978). A Textbook on Pharmacognosy (11th ed., pp. 22-40). Baillere Tindall, London.

Tsuchiya, H., \& Linuma, M. (2000). Reduction of Membrane fluidity by antibacterial sophoraflavone G. isolated from Sophora exigua. Phytomedicine, 7, 161-165. http://dx.doi.org/10.1016/S0944-7113(00)80089-6

Zy, E. A., Area, A., \& Aam, K. (2005). Antimicrobial activity of some medicinal plant extract in Palestine. Pak. J. Med. Sci., 21, 187-193.

\section{Copyrights}

Copyright for this article is retained by the author(s), with first publication rights granted to the journal.

This is an open-access article distributed under the terms and conditions of the Creative Commons Attribution license (http://creativecommons.org/licenses/by/3.0/). 